\title{
BMJ Open Prevalence of long-term health conditions in adults with autism: observational study of a whole country population
}

\author{
Ewelina Rydzewska, ${ }^{1}$ Laura Anne Hughes-McCormack, ${ }^{1}$ Christopher Gillberg, ${ }^{1,2}$
} Angela Henderson, ${ }^{1}$ Cecilia MacIntyre, ${ }^{3}$ Julie Rintoul, ${ }^{4}$ Sally-Ann Cooper ${ }^{1}$

To cite: Rydzewska E, HughesMcCormack LA, Gillberg C, et al. Prevalence of long-term health conditions in adults with autism: observational study of a whole country population. BMJ Open 2018;8:e23945. doi:10.1136/ bmjopen-2018-023945

- Prepublication history for this paper is available online. To view these files, please visit the journal online (http://dx.doi. org/10.1136/bmjopen-2018023945).

Received 2 May 2018

Revised 20 June 2018 Accepted 13 July 2018

Check for updates

(C) Author(s) (or their employer(s)) 2018. Re-use permitted under CC BY-NC. No commercial re-use. See rights and permissions. Published by BMJ.

${ }^{1}$ Institute of Health and Wellbeing, University of Glasgow, Glasgow, UK ${ }^{2}$ Gillbergcentrum/Gillberg NeuropsychiatryCentre,

Göteborgs Universitet/University of Gothenburg, Göteborg,

Sweden

${ }^{3}$ Census User Needs, Content and Benefits, National Records of Scotland, Edinburgh, UK

${ }^{4}$ Health and Social Care

Analysis, Scottish Government, Edinburgh, UK

\section{Correspondence to} Professor Sally-Ann Cooper; Sally-Ann.Cooper@glasgow. ac.uk

\section{ABSTRACT}

Objectives To investigate the prevalence of comorbid mental health conditions and physical disabilities in a whole country population of adults aged $25+$ with and without reported autism.

Design Secondary analysis of Scotland's Census, 2011 data. Cross-sectional study.

Setting General population.

Participants $94 \%$ of Scotland's population, including $6649 / 3746584$ adults aged 25+ reported to have autism. Main outcome measures Prevalence of six comorbidities: deafness or partial hearing loss, blindness or partial sight loss, intellectual disabilities, mental health conditions, physical disability and other condition; ORs $(95 \% \mathrm{Cl})$ of autism predicting these comorbidities, adjusted for age and gender; and OR for age and gender in predicting comorbidities within the population with reported autism.

Results Comorbidities were common: deafness/hearing loss-17.5\%; blindness/sight loss-12.1\%; intellectual disabilities-29.4\%; mental health conditions-33.0\%; physical disability - $30.7 \%$; other condition-34.1\%. Autism statistically predicted all of the conditions: OR 3.3 (95\% Cl 3.1 to 3.6) for deafness or partial hearing loss, OR 8.5 (95\% Cl 7.9 to 9.2) for blindness or partial sight loss, OR $94.6(95 \% \mathrm{Cl} 89.4$ to 100.0$)$ for intellectual disabilities, OR 8.6 ( $95 \% \mathrm{Cl} 8.2$ to 9.0 ) for mental health conditions, OR $6.2(95 \% \mathrm{Cl} 5.8$ to 6.6$)$ for physical disability and OR 2.6 (95\% Cl 2.5 to 2.8) for other condition. Contrary to findings within the general population, female gender predicted all conditions within the population with reported autism, including intellectual disabilities $(\mathrm{OR}=1.4)$.

Conclusions Clinicians need heightened awareness of comorbidities in adults with autism to improve detection and suitable care, especially given the added complexity of assessment in this population and the fact that hearing and visual impairments may cause additional difficulties with reciprocal communication which are also a feature of autism; hence posing further challenges in assessment.

\section{INTRODUCTION}

In the last 20 years, there has been a considerable increase in awareness of autism, but research on the comorbid conditions that
Strengths and limitations of this study

- Unique study of comorbidity in adults with reported autism in a whole country population.

- High response rate of $94 \%$ and systematic enquiry of everyone regarding autism and comorbidities (deafness, blindness, intellectual disabilities, mental health conditions, physical disability and other condition)

- Results of the study are generalisable to other adult populations in high-income countries.

- Findings are limited by the broad survey reporting of comorbidities, rather than detailed examinations.

adults with autism experience is limited. ${ }^{1}$ It has been suggested that some comorbidities are more common in children with autism than in the general population, ${ }^{2}$ but little research has been conducted with adults. Given the communicative and other problems that are a prominent feature of autism, the detection and management of comorbid conditions in people with autism is more complex than for other people. Therefore, it is important to know whether or not health problems are more common than in the general population. Empirically founded information about autism comorbidity would help to raise clinicians' awareness, and in turn increase identification and appropriate management.

Mental health has been studied more than physical health in adults with autism. However, systematic reviews reveal wide variation in reported prevalence of mental ill-health between studies. This is partly because almost all studies are based on clinical populations. Therefore, findings cannot be generalised with confidence, and additionally most study samples are small in size, and very few have drawn comparisons with the general population. It has 
been suggested that depression, ${ }^{3}$ bipolar disorder, ${ }^{4}$ suicidal thoughts/behaviour, ${ }^{5}$ non-affective psychosis $^{6}$ and attention-deficit hyperactivity disorder ${ }^{78}$ may be more common in adults with autism. A further study in North California, USA used medical records from a single health delivery provider of inpatient and outpatient medical and mental health services to identify $1507 / 1578658(0.1 \%)$ adults with autism, who were age and gender matched with controls without recorded autism. ${ }^{9}$ The study found that $19.2 \%$ of the adults with autism also had a record of intellectual disabilities, and $54 \%$ also had a record of one or more mental health conditions; with rates of individual mental conditions being 3-22 times higher for the adults with autism than their controls, and higher in the women with autism than in the men with autism. ${ }^{9}$ The study does, however, reflect the sampling frame; only those individuals with an existing record of autism in their medical records were identified as having autism.

Blindness/sight loss, deafness/hearing loss and physical disabilities may be more common in adults with autism than in other people, but most of the existing literature is drawn from non-representative and/or small populations, and without general population comparisons; hence leaving significant doubts as to the actual degree of over-representation. One exception is the North California study of a wide range of conditions recorded in medical records which found $16(1.1 \%)$ adults with autism to have low vision or blindness $(\mathrm{OR}=7.85)$ and $71(4.7 \%)$ with hearing impairment $(\mathrm{OR}=2.35) .{ }^{9}$ A further large study across 25 states in USA included 1002 adults known to have autism, but was drawn from the population receiving intellectual and developmental disabilities services; hence, it is clearly not representative of the population of adults with autism. ${ }^{10}$ Indeed, only 97 (9.7\%) participants did not have intellectual disabilities, so while $9.4 \%$ had visual impairments, $5.7 \%$ had hearing impairments and $6.0 \%$ had physical disability, these rates cannot be generalised to the wider population with autism. In a study of 92/305 adults aged 23-50 who had been identified to have autism in childhood in the $1980 \mathrm{~s}, 11$ of whom were deceased, participants answered questions on medical conditions and symptoms. ${ }^{11}$ Of the $92,73 \%$ had intellectual disabilities, $12 \%$ had hearing impairment and $25 \%$ visual impairment. ${ }^{11}$ Neither of these two studies included a general population comparison group. We were unable to identify any other studies on these conditions in adults with autism.

This study aimed to investigate the prevalence and predictors of deafness or partial hearing loss, blindness or partial sight loss, intellectual disabilities, mental health conditions, physical disability and other condition, in a whole country population of adults with reported autism aged 25+ compared with their peers without autism.

\section{METHODS}

\section{Data source}

Scotland's Census, 2011 provides information on Scotland's population on the Census date, 27 March 2011. Approval was gained from the Scottish Government for secondary analysis of the Census data. The Census includes the whole Scottish population, whether living in communal establishments (such as care homes and student halls of residence) or private households. Scotland's Census is one of the few country censuses that asks every person in the country whether or not they have autism, indeed it may be unique in this regard. One householder on behalf of all occupants in private households (the household reference person), and manager on behalf of all occupants in communal dwellings, was required to complete the Census information. The Census team also followed up non-responders and provided help to respond when needed. The Census form clearly states that it is a legal requirement to complete the form and non-completion or supplying false information attracts a $£ 1000$ fine. The Census is conducted every 10 years. In 2011, it was estimated to have achieved a $94 \%$ response rate. ${ }^{12}$ During the original data processing, the Census team adjusted for the $6 \%$ of the total population of Scotland for whom there was not completed Census data. This used a Census Coverage Survey (including around 40000 households) to estimate numbers and characteristics. The Coverage Survey and Census records were matched using automated and clerical matching. All Census individuals, including individuals reporting long-term health conditions, were deterministically matched to check if any records were duplicated. Individuals estimated to have been missed from the Census were then imputed, using a subset of characteristics from real individuals, including information on their health, to reach the $100 \%$ dataset completeness rate. The process of development of the Scotland's Census 2011 Edit and Imputation Methodology was adapted from the Office for National Statistics rigorous and systematic guidelines, which are available here: http://webarchive.nationalarchives.gov.uk/20160108193745/http://www.ons.gov.uk/ ons/guide-method/method-quality/survey-methodologybulletin/smb-69/index.html.

Further details on how the Census population estimates were arrived at are also available here: http:// www.scotlandscensus.gov.uk/documents/censusresults/ release1b/rellbmethodology.pdf.

Fulldetails of themethodologyand otherbackground information on Scotland's Census 2011 are available at: http:// www.scotlandscensus.gov.uk/supporting-information.

\section{CENSUS VARIABLES}

Self-reporting/proxy reporting was used to identify people with autism and other long-term conditions from the Census questionnaire, question 20: 'Do you have any of the following conditions which have lasted, or are expected to last, at least 12 months? Tick all that apply'. Respondents were given a choice of 10 response options: (1) deafness or partial hearing loss, (2) blindness or partial 
sight loss, (3) learning disability (eg, Down's syndrome), (4) learning difficulty (eg, dyslexia), (5) developmental disorder (eg, autistic spectrum disorder or Asperger's syndrome), (6) physical disability, (7) mental health condition, (8) long-term illness, disease or condition (9) other condition, (10) no condition. Following internal requirements for all Scotland's Census 2011 outputs stipulated by the National Records of Scotland, options 8 (long-term illness, disease or condition) and 9 (other condition) were merged and coded as one category of 'other condition'; thus, this term is used henceforth when referring to both these categories.

Importantly, while question 20: 'Do you have any of the following conditions which have lasted, or are expected to last, at least 12 months?', included the broad term developmental disorder, it only provided reference to 'autistic spectrum disorder' and 'Asperger's syndrome'. For the purpose of this study, we, therefore, interpreted responses to this question as relating to people who know they have these conditions, henceforth referred to as autism. Additionally, the question distinguished autism from learning disability (which in the UK is synonymous with the international term 'intellectual disabilities'), learning difficulty (which in the UK is synonymous with the international term 'specific learning disability' such as dyslexia) and mental health conditions, which are important distinctions.

As part of the methodological preparations for Scotland's Census, 2011, the General Register Office for Scotland commissioned Ipsos MORI Scotland to undertake cognitive question testing of the question 20 on long-term health conditions and disabilities. The aim was primarily to test whether the questions were answered accurately and willingly by respondents, and what changes might be required to improve data quality and/or the acceptability of the response options. Cognitive interviewing is a widely used approach to critically evaluate survey questionnaires. ${ }^{13}$ It enables researchers to modify survey material to enhance clarity. Retrospective probing was deemed to be the most appropriate of the different techniques for the Census. The questions were tested with 102 participants with a mix of gender and age, both with and without the health conditions and disabilities (including people with more than one of the conditions), to ensure accurate and willing completion, and included people with autism, intellectual disabilities, dyslexia, dyspraxia, speech impairment, mental health conditions (both milder and more serious) and other long-term conditions. This resulted in a redesign of the question on autism to 'developmental disorder, for example, autism spectrum disorder or Asperger's syndrome' in order to accurately capture specifically the data on autism. The questions on the other conditions tested (some of which, from a medical perspective, can be considered as developmental disorders) did not require any modification. Further information can be found at: http:// www.scotlandscensus.gov.uk/documents/research/ 2011-census-health-disability-questions.pdf http://www. scotlandscensus.gov.uk/documents/legislation/changesto-gov-statement-report.pdf

\section{DATA ANALYSIS}

We calculated the numbers and percentages of people with and without reported autism reporting deafness or partial hearing loss, blindness or partial sight loss, intellectual disabilities, mental health conditions, physical disability and other condition. We compared differences between the populations with and without reported autism using $\chi^{2}$ tests. Within the whole population, we then used six binary logistic regressions to calculate OR (95\% CI) of autism predicting having each of the six types of additional health conditions, adjusted for age group and gender. We then calculated the ORs for age group and gender in predicting each of the six comorbidities within the population with reported autism. All analyses were conducted with SPSS software V.22.

\section{PATIENT AND PUBLIC INVOLVEMENT}

The question on autism was included in Scotland's Census, 2011 at the behest of third sector organisations for people with autism. This study was undertaken by the Scottish Learning Disabilities Observatory, which has a specific remit for people with autism; its steering group includes partners from the third sector organisations. Results from this study will be disseminated for people with autism in easy-read version via the Scottish Learning Disabilities Observatory website and newsletters.

\section{RESULTS}

\section{Participant characteristics}

Scotland's Census 2011 included records on 5295403 people. There were 6649/3 $746584(0.2 \%)$ adults aged $25+$ recorded to have autism as defined here, 4610 $(69.3 \%)$ of whom were men and $2039(30.7 \%)$ women compared with $1776845(47.5 \%)$ men and 1963090 $(52.5 \%)$ women in the adult population without autism (table 1). The rate of autism was lowest in the oldest age groups (autism may be associated with reduced life expectancy).

\section{Prevalence of reported comorbidities}

The adult population with reported autism was significantly more likely to have each of the additional health conditions when compared with the population without reported autism, with each at the $\mathrm{p}<0.001$ level (table 2 ).

Table 3 shows the OR (95\% CI) of autism predicting each of the six conditions: OR 3.3 (3.1 to 3.6) for deafness or partial hearing loss, OR 8.5 (7.9 to 9.2) for blindness or partial sight loss, OR 94.6 (89.4 to 100.0) for intellectual disabilities, OR 8.6 (8.2 to 9.0) for mental health conditions, OR 6.2 (5.8 to 6.6) for physical disability and OR 2.6 (2.5 to 2.8) for other condition. Table 4 shows the OR $(95 \% \mathrm{CI})$ of age and gender in predicting comorbidities 
Table 1 Number and proportion of adults with autism by age and gender

\begin{tabular}{|c|c|c|c|}
\hline Age & Gender, n (\%) & Autism, n (\%) & Without autism, n (\%) \\
\hline \multirow[t]{3}{*}{ All adults aged $25+$} & Male $n=1781455(100)$ & $4610(0.3)$ & $1776845(99.7)$ \\
\hline & Female $n=1965129$ (100) & $2039(0.1)$ & 1963090 (99.9) \\
\hline & All $n=3746584$ (100) & $6649(0.2)$ & 3739935 (99.8) \\
\hline \multirow[t]{3}{*}{$25-34$ years } & Male $n=328607$ (100) & $1753(0.5)$ & 326854 (99.5) \\
\hline & Female $\mathrm{n}=338720$ (100) & $636(0.2)$ & $338084(99.8)$ \\
\hline & All $n=632488$ (100) & $2389(0.4)$ & 664938 (99.6) \\
\hline \multirow[t]{3}{*}{$35-44$ years } & Male $n=357670(100)$ & $1117(0.3)$ & $356553(99.7)$ \\
\hline & Female $n=377084(100)$ & $471(0.1)$ & $376613(99.9)$ \\
\hline & All $n=734754$ (100) & $1588(0.2)$ & 733166 (99.8) \\
\hline \multirow[t]{3}{*}{$45-54$ years } & Male $n=384517$ (100) & $890(0.2)$ & 383627 (99.8) \\
\hline & Female $n=402239(100)$ & $377(0.1)$ & 401862 (99.9) \\
\hline & All $n=786756$ (100) & $1267(0.2)$ & $785489(99.8)$ \\
\hline \multirow[t]{3}{*}{$55-64$ years } & Male $n=326922$ (100) & $474(0.1)$ & 326448 (99.9) \\
\hline & Female $n=340491$ (100) & $233(0.1)$ & 340258 (99.9) \\
\hline & All $n=667413(100)$ & $707(0.1)$ & 666706 (99.9) \\
\hline \multirow[t]{3}{*}{$65+$ years } & Male $n=383739(100)$ & $376(0.1)$ & $383363(99.9)$ \\
\hline & Female $\mathrm{n}=506595(100)$ & $322(0.1)$ & $506273(99.9)$ \\
\hline & All $n=890334(100)$ & $698(0.1)$ & 889636 (99.9) \\
\hline
\end{tabular}

within the population with autism aged $25+$. As one would expect, in the whole population, older age group statistically predicted blindness, deafness, physical disability and other condition, while age over 55 reduced the likelihood of intellectual disabilities (presumably due to early death), as did the $65+$ age group for mental health conditions. Female gender predicted blindness, mental health conditions, physical disability and other condition, while male gender predicted deafness and intellectual disabilities. Within the population with reported autism, older age group also statistically predicted blindness, deafness, physical disability and other condition, but not intellectual disabilities and mental health conditions. Contrary to findings in the general population, female gender predicted all conditions within the population with reported autism.

\section{DISCUSSION}

\section{Principal findings and comparison with existing literature}

Comorbidity is substantially greater in adults with reported autism than in other people; with ORs of 95 for intellectual disabilities, 9 for mental health conditions, 9 for deafness or partial hearing loss, 6 for physical disability, 3 for blindness or partial sight loss and 3 for other condition. All these conditions were common in adults with reported autism. These findings are important given the gap in evidence, as clinicians need to have heightened awareness of potential comorbidities in order to provide suitable investigation and management to maximise functioning and therefore improve quality of life. Findings on hearing and visual impairments for people with reported autism are perhaps particularly important, given the impact of these impairments on reciprocal communication, which is also an integral underlying impairment in autism. Clinical assessments of people with autism are more complex and take longer than for the average person. Nevertheless, our findings have demonstrated that investment in such assessments is necessary and important given the much higher prevalence of comorbidities.

We found mental health conditions in $33 \%$ of all adults with reported autism (range 23\%-37\% depending on age group; $27 \%-37 \%$ for men and $30 \%-40 \%$ for women). This high rate is lower than a previous report of $54 \%,{ }^{9}$ but their sample may have been biased to a more severely affected/complex population given their sampling, as shown by their lower identification rate for autism. We found $14 \%$ with hearing impairment (range $7 \%-46 \%$ depending on age group; $5 \%-44 \%$ for men and $11 \%-47 \%$ for women), and $12 \%$ with visual impairments (range 7\%-30\% depending on age group; $7 \%-27 \%$ for men and $10 \%-35 \%$ for women), notably higher than the rates recorded in medical records reported in the North California study $(4.7 \%$ and $1.1 \%$ respectively, though ORs were not dissimilar) ${ }^{9}$ likely reflecting the different study methodologies. In the study of 92 adults with autism, $12 \%$ had hearing impairment and $25 \%$ visual impairment, ${ }^{11}$ respectively, though the study was much smaller and of limited age range than in our study. A high rate of intellectual disabilities in children with autism has been described previously; we have now quantified the extent of this-29\% (25\%-32\% depending on age group; $22 \%-35 \%$ for men and $31 \%-42 \%$ for women) -in 


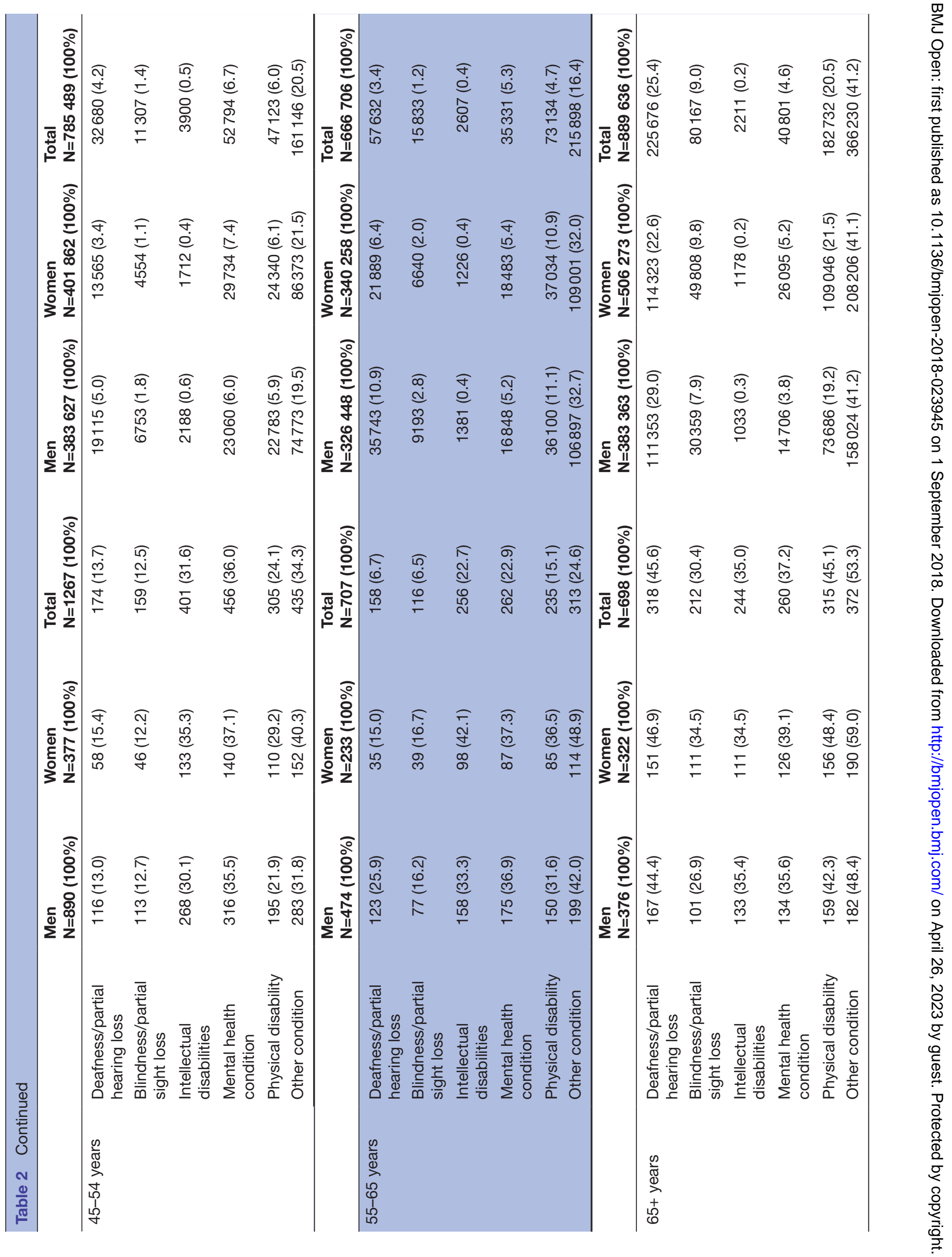


Table 3 Results of six regressions showing independent predictors of comorbid conditions in the whole adult population

\section{Condition}

Deafness or partial hearing loss

\begin{tabular}{|c|c|c|}
\hline & No autism (reference) & - \\
\hline & Autism & 3.32 (3.075 to 3.585$)$ \\
\hline \multicolumn{3}{|c|}{ Age } \\
\hline & 25-34 (reference) & - \\
\hline & $35-44$ & $1.768(1.721$ to 1.817$)$ \\
\hline & $45-54$ & 3.55 (3.464 to 3.638 ) \\
\hline & $55-64$ & 7.742 (7.563 to 7.926$)$ \\
\hline & $65+$ & 28.621 (27.987 to 29.269 ) \\
\hline \multicolumn{3}{|c|}{ Gender } \\
\hline & Male (reference) & - \\
\hline & Female & 0.683 (0.678 to 0.688$)$ \\
\hline & Constant & 0.015 \\
\hline \multirow[t]{13}{*}{ Blindness or partial sight loss } & Autism & \\
\hline & No autism (reference) & - \\
\hline & Autism & 8.514 (7.861 to 9.220$)$ \\
\hline & Age & \\
\hline & 25-34 (reference) & - \\
\hline & $35-44$ & $1.36(1.308$ to 1.414$)$ \\
\hline & $45-54$ & 2.335 (2.254 to 2.419$)$ \\
\hline & $55-64$ & 3.882 (3.752 to 4.016$)$ \\
\hline & $65+$ & 15.769 (15.287 to 16.267$)$ \\
\hline & Gender & \\
\hline & Male (reference) & - \\
\hline & Female & 1.018 (1.006 to 1.030$)$ \\
\hline & Constant & 0.006 \\
\hline \multirow[t]{13}{*}{ Intellectual disabilities } & Autism & \\
\hline & No autism (reference) & - \\
\hline & Autism & 94.571 (89.409 to 100.032$)$ \\
\hline & Age & \\
\hline & 25-34 (reference) & - \\
\hline & $35-44$ & 1.101 (1.050 to 1.154$)$ \\
\hline & $45-54$ & 1.187 (1.134 to 1.243$)$ \\
\hline & $55-64$ & 0.958 (0.910 to 1.008$)$ \\
\hline & $65+$ & 0.631 (0.598 to 0.665$)$ \\
\hline & Gender & \\
\hline & Male (reference) & - \\
\hline & Female & 0.812 (0.788 to 0.838$)$ \\
\hline & Constant & 0.005 \\
\hline \multirow[t]{6}{*}{ Mental health condition } & Autism & \\
\hline & No autism (reference) & - \\
\hline & Autism & 8.595 (8.163 to 9.050$)$ \\
\hline & Age & \\
\hline & 25-34 (reference) & - \\
\hline & $35-44$ & 1.404 (1.384 to 1.424$)$ \\
\hline
\end{tabular}

Autism

No autism (reference)

Autism

25-34 (reference)

35-44

45-54

ender

Male (reference)

Female

Autism

No autism (reference)

Autism

25-34 (reference)

35-44

$65+$

\section{OR $(95 \% \mathrm{Cl})$}

1.768 (1.721 to 1.817$)$

3.55 (3.464 to 3.638 )

7.742 (7.563 to 7.926$)$

(27.987 to 29.269)

(0.678 to 0.688)

1.36 (1.308 to 1.414$)$

(2.254 to 2.419 )

Gender

le (reference)

Female

Autism

No autism (reference)

ge

25-34 (reference)

1.101 (1.050 to 1.154 )

1.187 (1.134 to 1.243 )

0.958 (0.910 to 1.008$)$

65

Continued 
Table 3 Continued

\begin{tabular}{|c|c|c|}
\hline Condition & Variable & OR $(95 \% \mathrm{Cl})$ \\
\hline & $45-54$ & 1.383 (1.364 to 1.403$)$ \\
\hline & $55-64$ & $1.076(1.060$ to 1.093$)$ \\
\hline & $65+$ & 0.913 (0.899 to 0.926$)$ \\
\hline & Gender & \\
\hline & Male (reference) & - \\
\hline & Female & $1.247(1.236$ to 1.258$)$ \\
\hline & Constant & 0.046 \\
\hline \multirow[t]{13}{*}{ Physical disability } & Autism & \\
\hline & No autism (reference) & - \\
\hline & Autism & 6.21 (5.841 to 6.603$)$ \\
\hline & Age & \\
\hline & 25-34 (reference) & - \\
\hline & $35-44$ & 2.138 (2.091 to 2.186$)$ \\
\hline & $45-54$ & 3.786 (3.708 to 3.866 ) \\
\hline & $55-64$ & 7.311 (7.164 to 7.460$)$ \\
\hline & $65+$ & 15.288 (14.994 to 15.587$)$ \\
\hline & Gender & \\
\hline & Male (reference) & - \\
\hline & Female & 1.064 (1.056 to 1.072$)$ \\
\hline & Constant & 0.016 \\
\hline \multirow[t]{13}{*}{ Other condition } & Autism & \\
\hline & No autism (reference) & - \\
\hline & Autism & 2.64 (2.502 to 2.786$)$ \\
\hline & Age & \\
\hline & 25-34 (reference) & - \\
\hline & $35-44$ & 1.709 (1.690 to 1.728$)$ \\
\hline & $45-54$ & 2.839 (2.810 to 2.868$)$ \\
\hline & $55-64$ & 5.269 (5.217 to 5.323$)$ \\
\hline & $65+$ & 7.671 (7.597 to 7.745$)$ \\
\hline & Gender & \\
\hline & Male (reference) & - \\
\hline & Female & 1.068 (1.063 to 1.074$)$ \\
\hline & Constant & 0.088 \\
\hline
\end{tabular}

a much larger study of adults. There are few other studies with which we can draw comparisons, and we identified none on physical disability in adults with autism with which we could compare the high rate of $24 \%$ for all adults aged $25+$ (range $15 \%-45 \%$ depending on age group; $14 \%-42 \%$ for men and $24 \%-45 \%$ for women).

A view has been expressed that autism is currently underdiagnosed in more intellectually able females compared with males. ${ }^{14}$ We found that $34 \%$ of women compared with only $27 \%$ of men with autism reported accompanying intellectual disabilities, so the female population with autism was intellectually less able than the male population with autism. Our findings may, therefore, provide some evidence to support the view of underdiagnosis of autism in the more intellectually able women. Alternatively, women and men with autism may actually be intellectually different.

We have previously reported Census findings on comorbidities for people with intellectual disabilities. ${ }^{15}$ Many conditions are related to intellectual level, with there being a gradient across the whole spread of intelligence (not just intellectual disabilities). ${ }^{16}$ Given the lower average intelligence we found in the autistic women than the autistic men, one might expect more comorbidities to be found in the women than the men. Indeed, the women with autism had higher rates of all 
Table 4 Results of six regressions showing independent predictors of comorbid conditions in the adult population with autism

\section{Condition}

Variable

OR $(95 \% \mathrm{Cl})$

Deafness or partial hearing loss

Age

25-34 (reference)

$35-44 \quad 1.189$ (0.934 to 1.514$)$

$45-54$

2.178 (1.738 to 2.731$)$

$55-64$

3.92 (3.088 to 4.975$)$

$65+$

11.179 (8.972 to 13.929$)$

Gender

Male (reference)

Female

1.169 (1.001 to 1.365$)$

Constant

0.07

Blindness or partial sight loss

Age

$\begin{array}{ll}25-34 \text { (reference) } & - \\ 35-44 & 1.179(0.936 \text { to } 1.485) \\ 45-54 & 1.75(1.397 \text { to } 2.192) \\ 55-64 & 2.378(1.851 \text { to } 3.056) \\ 65+ & 5.148(4.117 \text { to } 6.438)\end{array}$

Gender

Male (reference)

Female

1.232 (1.051 to 1.443$)$

Constant

0.077

Intellectual disabilities

Age

25-34 (reference)

35-44

1.163 (1.008 to 1.343$)$

45-54

1.363 (1.172 to 1.584$)$

55-64

1.656 (1.384 to 1.981 )

$65+$

1.505 (1.254 to 1.807$)$

Gender

Male (reference)

Female

1.354 (1.209 to 1.516$)$

Constant

0.309

Mental health condition

Age

25-34 (reference)

35-44

1.455 (1.269 to 1.668$)$

45-54

1.485 (1.284 to 1.719 )

55-64

1.548 (1.297 to 1.849 )

$65+$

1.531 (1.280 to 1.832 )

Gender

Male (reference)

Female

1.155 (1.034 to 1.291$)$

Constant

0.362

Physical disability

Age

$25-34$ (reference)
$35-44$
$45-54$
$55-64$

1.22 (1.038 to 1.434$)$

1.487 (1.258 to 1.758 )

2.312 (1.913 to 2.795 )

Continued 


\begin{tabular}{lcc}
\hline Table 4 Continued & Variable & OR (95\% Cl) \\
\hline Condition & $65+$ & 3.634 (3.022 to 4.370) \\
& Gender & - \\
& Male (reference) & 1.504 (1.333 to 1.697) \\
& Female & 0.187 \\
Other condition & Constant & - \\
& Age & - \\
& $25-34$ (reference) & $1.276(1.109$ to 1.467$)$ \\
& $35-44$ & $1.419(1.224$ to 1.645$)$ \\
& $45-54$ & $2.134(1.792$ to 2.542$)$ \\
& $55-64$ & 2.901 (2.433 to 3.459) \\
& $65+$ & - \\
& Gender & 1.563 (1.400 to 1.745) \\
& Male (reference) & 0.321 \\
\hline
\end{tabular}

six comorbidities than did the men with autism; OR of female gender predicting each of the six comorbidities was greater for all conditions (except mental health) in the population with autism compared with the whole population, and indeed reversed for deafness and intellectual disabilities which were more common in men in the whole population. Alternatively, these findings could support the view that in some cases it is the concept of 'Autism Plus' (ie, autism co-occurring with any other major neurodevelopmental disorder), ${ }^{17}$ which ultimately results in people receiving a diagnosis of autism. While this Plus element of co-occurring conditions is currently often neglected in assessment, diagnosis and intervention, in some populations, possibly including women, it may be the initial or primary reason for considering a diagnosis of autism.

\section{Strengths and limitations}

We believe this study to be unique in including the whole population of a country, with a high response rate, and systematic enquiry of everyone regarding autism and selected long-term conditions. The results of this study are generalisable to other adult populations in high-income countries. The concept of autistic spectrum disorder has broadened in recent years; hence, our findings relate to the narrower definition that was used to diagnose autism in the past, as the study is one of adults who most likely were originally diagnosed in childhood. This accounts for the $0.2 \%$ identified prevalence; more recent studies conducting autism assessments have reported higher prevalence. ${ }^{18}$ It is important to note that undiagnosed adults with milder forms of autism may have lower levels of comorbidity than those with more severe autism. Limitations may include the use of the term developmental disorder in the Census, although the clarification of this term provided on the Census form included only autistic spectrum disorder and Asperger's syndrome, and the phrasing of the question was carefully selected specifically to capture autism, from results of the cognitive question testing procedure. Furthermore, this category was distinguished from intellectual disabilities, specific learning disability and mental health conditions, and tested with people with all these conditions. Hence, we consider that respondents will have replied accordingly, that is, responded regarding autism. However, we have no further means to check this on the whole population. Furthermore, respondents reported whether or not each person was known to have autism rather than each person having an assessment for autism, so some reporting error is possible. Given the large number of households, we are unable to state how each household reference person approached completing the Census form, although cognitive question testing was completed with a broad range of 70 respondents on the whole questionnaire in advance of the Census (in addition to the 102 respondents who completed cognitive question testing interviews specifically on the health questions). The Census form was also broad-brush in its questioning rather than including detailed subquestions on each of the six categories of health conditions. Finally, while we describe the imputation process, we cannot state with certainty whether or not the imputed $6 \%$ of records contained the same, higher or lower proportion of adults with autism, but note that this missing $6 \%$ is a small proportion overall. Despite this, we believe the results of this study are generalisable to other high-income countries, as well as filling a significant gap in existing research on the prevalence of long-term health conditions in adults with autism. 


\section{Implications for clinicians}

This study advances our knowledge of comorbidities in adults with autism, which is otherwise somewhat invisible in previous studies. Adults with reported autism have very high rates of comorbid physical disabilities as well as mental health conditions. Hearing and visual impairments are also very common, and their impact on reciprocal communication, especially if undiagnosed/ unattended, may compound core features of autism. Clinicians require a heightened awareness of this, especially given the greater complexity of health assessments in adults with autism compared with other people. It is essential to have accurate information on the prevalence of comorbid conditions in adults with autism in order to accurately plan for service provision and to tackle health inequalities. Our study is large scale and robust in design, but requires replication given the relative lack of previous studies on this topic.

Acknowledgements We thank the National Records of Scotland for assisting with the data analysis and dissemination stages of the project.

Contributors ER analysed the data, jointly interpreted it and wrote the first draft of the manuscript. LAH-M, CG and AH jointly interpreted the data and contributed to the manuscript. CM and JR worked on the Census, jointly interpreted the data and contributed to the manuscript. S-AC conceived the project, interpreted the data and contributed to the manuscript. All authors approved the final version of the manuscript. S-AC is the study guarantor.

Funding This work was supported by the Scottish Government via the Scottish Learning Disabilities Observatory.

Disclaimer The funder had no role in the study design, collection, analyses and interpretation of data, in writing the report, nor in the decision to submit the article for publication.

Competing interests None declared.

Patient consent Not required.

Ethics approval Permission to access data was granted by the Scottish Government.

Provenance and peer review Not commissioned; externally peer reviewed.

Data sharing statement Data available at: http://www.scotlandscensus.gov.uk/ ods-web/data-warehouse.html\#additionaltab.

Open access This is an open access article distributed in accordance with the Creative Commons Attribution Non Commercial (CC BY-NC 4.0) license, which permits others to distribute, remix, adapt, build upon this work non-commercially, and license their derivative works on different terms, provided the original work is properly cited, appropriate credit is given, any changes made indicated, and the use is non-commercial. See: http://creativecommons.org/licenses/by-nc/4.0/.

\section{REFERENCES}

1. Perkins EA, Berkman KA. Into the unknown: aging with autism spectrum disorders. Am J Intellect Dev Disabil 2012;117:478-96.

2. Gillberg C, Billstedt E. Autism and asperger syndrome: coexistence with other clinical disorders. Acta Psychiatr Scand 2000;102:321-30.

3. Stewart ME, Barnard L, Pearson J, et al. Presentation of depression in autism and Asperger syndrome: a review. Autism 2006;10:103-16.

4. Vannucchi G, Masi G, Toni C, et al. Bipolar disorder in adults with asperger's syndrome: a systematic review. J Affect Disord 2014;168:151-60.

5. Segers M, Rawana J. What do we know about suicidality in autism spectrum disorders? A systematic review. Autism Res 2014;7:507-21.

6. Padgett FE, Miltsiou E, Tiffin PA. The co-occurrence of nonaffective psychosis and the pervasive developmental disorders: a systematic review. J Intellect Dev Disabil 2010;35:187-98.

7. Johnston K, Dittner A, Bramham J, et al. Attention deficit hyperactivity disorder symptoms in adults with autism spectrum disorders. Autism Res 2013;6:225-36.

8. Gillberg IC, Helles A, Billstedt E, et al. Boys with asperger syndrome grow up: psychiatric and neurodevelopmental disorders 20 years after initial diagnosis. J Autism Dev Disord 2016;46:74-82.

9. Croen LA, Zerbo O, Qian Y, et al. The health status of adults on the autism spectrum. Autism 2015;19:814-23.

10. Hewitt AS, Stancliffe RJ, Johnson Sirek A, et al. Characteristics of adults with autism spectrum disorder who use adult developmenta disability services: results from 25 US states. Res Autism Spectr Disord 2012;6:741-51.

11. Jones KB, Cottle K, Bakian A, et al. A description of medical conditions in adults with autism spectrum disorder: a follow-up of the 1980s Utah/UCLA Autism Epidemiologic Study. Autism 2016;20:551-61.

12. National Records of Scotland (NRS). 2011 Census Release 1C - How the 2011 Census population estimates were obtained. Edinburgh: National Records of Scotland, 2013.

13. Wills GB. Cognitive interviewing: a tool for improving questionnaire design. Thousand Oaks: Sage Publications, 2005.

14. Dworzynski K, Ronald A, Bolton P, et al. How different are girls and boys above and below the diagnostic threshold for autism spectrum disorders? J Am Acad Child Adolesc Psychiatry 2012;51:788-97.

15. Hughes-McCormack LA, Rydzewska E, Henderson A, et al. Prevalence of mental health conditions and relationship with general health in a whole-country population of people with intellectual disabilities compared with the general population. BJPsych Open 2017;3:243-8.

16. Wraw C, Deary IJ, Gale CR, et al. Intelligence in youth and health at age 50. Intelligence 2015;53:23-32.

17. Gillberg C, Fernell E. Autism plus versus autism pure. J Autism Dev Disord 2014;44:3274-6.

18. Brugha TS, Spiers N, Bankart J, et al. Epidemiology of autism in adults across age groups and ability levels. Br J Psychiatry 2016;209:498-503. 
Corrections: Prevalence of long-term health conditions in adults with autism: observational study of a whole country population

Rydzewska E, Hughes-McCormack LA, Gillberg C, et al. Prevalence of long-term health conditions in adults with autism: observational study of a whole country population BMJ Open 2018;8:e023945. doi: 10.1136/bmjopen-2018-023945.

This article was previously published with some errors.

In result section of the abstract, the percentage of deafness/hearing loss, physical disability and the OR for mental health conditions are incorrect.

deafness/hearing loss should be $14.1 \%$ instead of $17.5 \%$

physical disability should be $24.0 \%$ instead of $30.7 \%$

OR for mental health conditions should be OR 8.6 (95\% CI 8.2 to 9.1 ) instead of OR $8.6(95 \%$ CI 8.2 to 9.0$)$.

On the prevalence of reported comorbidities section (page 3) it reads:

Table 3 shows the OR (95\% CI) of autism predicting each of the six conditions: OR 3.3 (3.1 to 3.6) for deafness or partial hearing loss, OR 8.5 (7.9 to 9.2) for blindness or partial sight loss, OR 94.6 (89.4 to 100.0) for intellectual disabilities, OR 8.6 (8.2 to 9.0) for mental health conditions, OR 6.2 (5.8 to 6.6) for physical disability and OR 2.6 (2.5 to 2.8) for other condition.

It should read:

Table 3 shows the OR (95\% CI) of autism predicting each of the six conditions: OR 3.3 (3.1 to 3.6) for deafness or partial hearing loss, OR 8.5 (7.9 to 9.2) for blindness or partial sight loss, OR 94.6 (89.4 to 100.0) for intellectual disabilities, OR 8.6 (8.2 to 9.1) for mental health conditions, OR 6.2 (5.8 to 6.6) for physical disability and OR 2.6 (2.5 to 2.8) for other condition.

On the discussion section, first sentence of the first paragraph reads:

Comorbidity is substantially greater in adults with reported autism than in other people; with ORs of 95 for intellectual disabilities, 9 for mental health conditions, 9 for deafness or partial hearing loss, 6 for physical disability, 3 for blindness or partial sight loss and 3 for other condition.

It should read:

Comorbidity is substantially greater in adults with reported autism than in other people; with ORs of 95 for intellectual disabilities, 9 for mental health conditions, 9 for blindness or partial sight loss, 6 for physical disability, 3 for deafness or partial hearing loss and 3 for other condition.

On the discussion section, third sentence of the second paragraph reads:

We found $14 \%$ with hearing impairment (range $7 \%-46 \%$ depending on age group; $5 \%-44 \%$ for men and $11 \%-47 \%$ for women), and $12 \%$ with visual impairments (range $7 \%-30 \%$ depending on age group; $7 \%-27 \%$ for men and $10 \%-35 \%$ for women), notably higher than the rates recorded in medical records reported in the North California study ( $4.7 \%$ and $1.1 \%$ respectively, though ORs were not dissimilar) 9 likely reflecting the different study methodologies. 
It should read:

We found $14 \%$ with hearing impairment (range $7 \%-46 \%$ depending on age group; $5 \%-44 \%$ for men and $9 \%-47 \%$ for women), and $12 \%$ with visual impairments (range $7 \%-30 \%$ depending on age group; $7 \%-27 \%$ for men and 10\%-35\% for women), notably higher than the rates recorded in medical records reported in the North California study $(4.7 \%$ and $1.1 \%$ respectively, though ORs were not dissimilar)9 likely reflecting the different study methodologies.

On the discussion section, fifth sentence of the second paragraph reads:

A high rate of intellectual disabilities in children with autism has been described previously; we have now quantified the extent of this-29\% (25\%-32\% depending on age group; $22 \%-35 \%$ for men and $31 \%-42 \%$ for women) - in a much larger study of adults.

It should read:

A high rate of intellectual disabilities in children with autism has been described previously; we have now quantified the extent of this-29\% (23\%-35\% depending on age group; $22 \%-35 \%$ for men and $31 \%-42 \%$ for women) - in a much larger study of adults.

On the discussion section, sixth sentence of the second paragraph reads:

There are few other studies with which we can draw comparisons, and we identified none on physical disability in adults with autism with which we could compare the high rate of $24 \%$ for all adults aged 25+ (range 15\%-45\% depending on age group; $14 \%-42 \%$ for men and $24 \%-45 \%$ for women).

It should read:

There are few other studies with which we can draw comparisons, and we identified none on physical disability in adults with autism with which we could compare the high rate of $24 \%$ for all adults aged $25+$ (range $15 \%-45 \%$ depending on age group; $14 \%-42 \%$ for men and $24 \%-48 \%$ for women).

In table 1, the total number for the gender of 25-34 years is 667327 instead of 632488 .

Open access This is an open access article distributed in accordance with the Creative Commons Attribution Non Commercial (CC BY-NC 4.0) license, which permits others to distribute, remix, adapt, build upon this work non-commercially, and license their derivative works on different terms, provided the original work is properly cited, appropriate credit is given, any changes made indicated, and the use is non-commercial. See: http://creativecommons.org/licenses/by-nc/4.0/.

(c) Author(s) (or their employer(s)) 2018. Re-use permitted under CC BY-NC. No commercial re-use. See rights and permissions. Published by BMJ.

BMJ Open 2018;8:e23945corr1. doi:10.1136/bmjopen-2018-023945corr1

Check for updates 